\title{
Catalisadores de Automóvel: Caracterização, Reciclagem e Recuperação de Metals Preciosos
}

\author{
A. P. Paiva ${ }^{1}$, C. A. Nogueira ${ }^{2 *}$, A. M. R. Costa $^{3}$, M. C. Costa ${ }^{4}$ \\ ${ }^{1}$ Centro de Química e Bioquímica, Departamento de Química e Bioquímica, Faculdade de Ciências da Universidade de Lisboa \\ ${ }^{2}$ Laboratório Nacional de Energia e Geologia, I.P. \\ ${ }^{3}$ Centro de Investigação em Química do Algarve, Departamento de Química e Farmácia, \\ Faculdade de Ciências e de Tecnologia, Universidade do Algarve \\ ${ }^{4}$ Centro de Ciências do Mar, Departamento de Química e Farmácia, Faculdade de Ciências e de Tecnologia, Universidade do Algarve \\ carlos.nogueira@lneg.pt
}

\begin{abstract}
Os catalisadores de automóvel desempenham um papel importante no tratamento dos gases de escape dos veículos, minimizando as emissões de substâncias nocivas para o ambiente. No final do seu ciclo de vida constituem resíduos que devem ser reciclados, não só por razões ambientais, mas também económicas e de conservação de recursos. Os agentes catalíticos destes dispositivos são os metais nobres do grupo da platina (Pt, Pd e Rh) cuja recuperação é crucial pelo seu valor e raridade. Neste artigo apresenta-se uma descrição do funcionamento, composição e de processos para a reciclagem de catalisadores de automóvel, bem como alguns resultados de um projecto de investigação em curso que visa contribuir para o desenvolvimento de operações hidro-metalúrgicas, como a lixiviação e a extracção por solventes, aplicáveis aos metais nobres contidos nestes resíduos. Estudou-se a lixiviação em meio de $\mathrm{HCl}$, na presença de um oxidante, demonstrando-se o efeito de variáveis processuais como a concentração dos reagentes e a temperatura nos rendimentos de lixiviação dos metais. Foram também desenvolvidos extractantes (diamidas), que extraem eficiente e selectivamente os metais nobres de meios cloretados, possibilitando a sua separação e recuperação.
\end{abstract}

\section{INTRODUÇÃO}

A emissão de gases associada aos motores dos veículos automóveis tem sido, desde há vários anos, uma preocupação crescente. Para além dos componentes principais resultantes da combustão, água e dióxido de carbono, formam-se também outros compostos que, sendo potencialmente tóxicos, requerem particular atenção. O oxigénio e o nitrogénio reagem para formar óxido nítrico, reacção favorecida às altas temperaturas de funcionamento dos motores, (Eq. 1).

$$
\mathrm{N}_{2}(\mathrm{~g})+\mathrm{O}_{2}(\mathrm{~g}) \rightarrow 2 \mathrm{NO}(\mathrm{g})
$$

Quando libertado para a atmosfera, o NO reage rapidamente com oxigénio para formar óxidos de nitrogénio, genericamente designados por $\mathrm{NO}_{\mathrm{x}}$. Estes compostos, juntamente com o monóxido de carbono e os hidrocarbonetos (HC's) do combustível não queimado, constituem os componentes dos gases de escape que devem ser evitados.

Devido aos impactos negativos para o ambiente, quer nos efeitos directos sobre a saúde mas também nos grandes impactos globais (e.g. alterações climáticas), têm sido progressivamente desenvolvidas diversas tecnologias para minimizar essas emissões. Este combate tem sido prosseguido tanto ao nível da produção de motores mais eficientes e menos poluentes, bem como através da aplicação de tecnologias de tratamento dos gases de escape por utilização de conversores catalíticos. A aposta da indústria automóvel na promoção dos veículos a diesel foi também uma medida no mesmo sentido, dado que este tipo de motores é considerado mais "limpo", por serem mais eficientes e económicos. Contudo, embora os motores a diesel produzam significa- tivamente menos monóxido de carbono e hidrocarbonetos do que os motores a gasolina, o mesmo não acontece para as emissões de gases nitrosos $\left(\mathrm{NO}_{\mathrm{x}}\right)$ e de partículas.

A utilização de catalisadores no tratamento dos gases de exaustão é, assim, essencial para reduzir os efeitos nocivos das emissões. Os agentes catalíticos utilizados nestes dispositivos são os metais do grupo da platina (platinum-group metals, PGM’s), nomeadamente a platina, o paládio e o ródio. A utilização destes metais deve-se às excelentes propriedades catalíticas que apresentam, mas também à sua estabilidade electroquímica e térmica. São, contudo, metais preciosos, caros e raros, cuja gestão eficiente é crucial para assegurar a continuidade do seu fornecimento nos mercados.

Pode considerar-se que foi na década de 1960 que se iniciaram os sistemas de controlo dos gases de exaustão dos veículos, através de dispositivos de válvulas de retorno dos gases, que permitiram melhores rendimentos de queima dos combustíveis e reduziram as emissões de HC's. Mais tarde, na década seguinte, assistiu-se à introdução de sistemas electrónicos, que possibilitaram um controlo mais rigoroso da injecção. Foi também na década de 1970 que se deu a introdução da primeira geração de catalisadores, essencialmente com a função de converter o CO e os HC's, razão por que foram designados de catalisadores de oxidação ou two-way-catalysts. A platina foi o metal inicialmente utilizado neste tipo de catalisadores. Na década de 1980 foram introduzidos os catalisadores de platina/ródio, sendo o segundo metal utilizado essencialmente para a redução dos $\mathrm{NO}_{\mathrm{x}}$. Surgiram nesta década os primeiros catalisadores do tipo three-way-catalysts, concebidos para desem- 
penhar várias funções: (a) a redução dos $\mathrm{NO}_{x}$, na zona mais próxima do motor; (b) a oxidação do CO e dos HC's numa zona mais afastada; (c) o controlo da injecção do combustível e do comburente (nomeadamente ajustando o respectivo rácio) através da utilização de sensores para a análise dos gases. Nas décadas seguintes assistiu-se a um desenvolvimento progressivo dos catalisadores, a vários níveis: (a) na melhoria dos materiais constituintes (adição de estabilizadores e de materiais de reserva de oxigénio); (b) na melhoria da construção e da resistência mecânica/térmica; (c) na utilização de sensores nos gases e de electrónica avançada para optimização dos sistemas de injecção; (d) na diminuição do teor de metais preciosos. Registou-se também a introdução, em larga escala e a partir da década de 1990, dos catalisadores de paládio/ ródio e, mais tarde, dos catalisadores contendo somente paládio, possibilitada pela utilização massificada de gasolinas sem chumbo [1].

\section{CaracterizaÇ̃̃o dos Catalisadores}

\subsection{Funcionamento de um CATAlisador}

Os gases de exaustão, contendo hidrocarbonetos leves, monóxido de carbono e óxidos nitrosos, são convertidos em dióxido de carbono, água e nitrogénio [1] através de reacções de oxidação e redução ocorridas na superfície do catalisador e promovidas pelos metais do grupo da platina (PGM’s).

Reacções de redução:

$$
\begin{aligned}
& \mathrm{NO}_{x}(g)+x \mathrm{CO}(\mathrm{g}) \rightarrow 1 / 2 \mathrm{~N}_{2}(\mathrm{~g})+\mathrm{x} \mathrm{CO}_{2}(\mathrm{~g}) \\
& \mathrm{NO}_{\mathrm{x}}(\mathrm{g})+\mathrm{x} \mathrm{H}_{2}(\mathrm{~g}) \rightarrow 1 / 2 \mathrm{~N}_{2}(\mathrm{~g})+\mathrm{x} \mathrm{H}_{2} \mathrm{O}(\mathrm{g}) \\
& (2 \mathrm{y}+\mathrm{n} / 2) \mathrm{NO}(\mathrm{g})+\mathrm{C}_{\mathrm{y}} \mathrm{H}_{\mathrm{n}}(\mathrm{g}) \rightarrow(\mathrm{y}+\mathrm{n} / 4) \mathrm{N}_{2}(\mathrm{~g})+\mathrm{y} \mathrm{CO}_{2} \\
& (\mathrm{~g})+\mathrm{n} / 2 \mathrm{H}_{2} \mathrm{O}(\mathrm{g})
\end{aligned}
$$

Reacções de oxidação:

$$
\mathrm{C}_{\mathrm{y}} \mathrm{H}_{\mathrm{n}}(\mathrm{g})+(\mathrm{y}+\mathrm{n} / 4) \mathrm{O}_{2}(\mathrm{~g}) \rightarrow \mathrm{y} \mathrm{CO}_{2}(\mathrm{~g})+\mathrm{n} / 2 \mathrm{H}_{2} \mathrm{O}(\mathrm{g})
$$

$$
\begin{aligned}
& \mathrm{CO}(\mathrm{g})+1 / 2 \mathrm{O}_{2}(\mathrm{~g}) \rightarrow \mathrm{CO}_{2}(\mathrm{~g}) \\
& \mathrm{CO}(\mathrm{g})+\mathrm{H}_{2} \mathrm{O}(\mathrm{g}) \rightarrow \mathrm{CO}_{2}(\mathrm{~g})+\mathrm{H}_{2}(\mathrm{~g})
\end{aligned}
$$

Qualquer um dos PGM's pode catalisar estas reacções. No entanto, a sua eficiência não é igual, e a escolha dos metais a usar, ou das suas combinações, não é a isso alheia [2,3]. Factores como a eficiência dos motores (e, assim, a composição final dos gases), a resistência química/ térmica e o custo são muito importantes na concepção da composição de um catalisador. Actualmente assiste-se a uma progressiva substituição da platina pelo paládio em muitos catalisadores.

\subsection{COMPONENTES dOS CATALISADORES}

Um catalisador de gases de exaustão é constituído por um ou mais monólitos de material cerâmico ou metálico, com forma cilíndrica (e secção circular ou oval), protegidos por um invólucro metálico de aço (Figura 1). Os monólitos têm uma estrutura perfurada, do tipo "favo-de-mel", por onde os gases são canalizados. Os três principais componentes dos monólitos são a fase de suporte (matriz), a camada superficial de revestimento e os PGM's (elementos catalíticos) inseridos no revestimento.

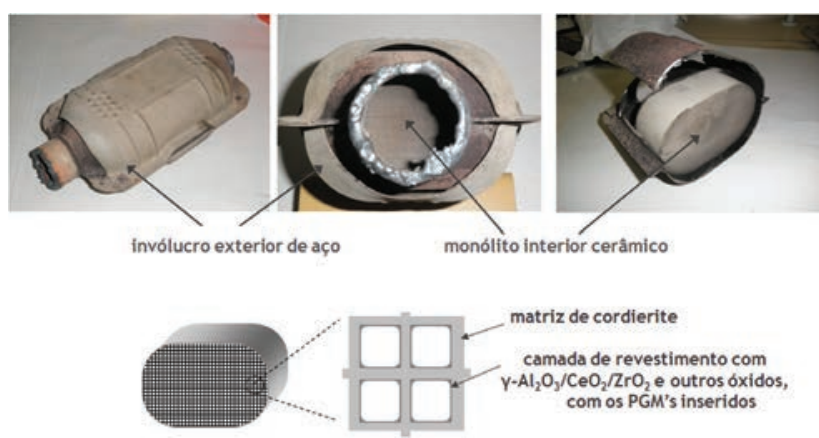

Figura 1 - Principais componentes de um catalisador auto de matriz cerâmica

Os suportes cerâmicos são constituídos por cordierite, um ciclossilicato de magnésio, ferro e alumínio, enquanto os metálicos são de aço inox. Os mais comuns são os suportes de matriz cerâmica, embora os de matriz metálica sejam mais eficientes numa perspectiva de condução de calor e promoção das reacções catalíticas em tempos mais curtos. A camada superficial é vulgarmente constituída por alumina-ץ e vários outros óxidos metálicos, destacando-se os de cério e de zircónio.

A Figura 2 ilustra a composição ponderal típica de um catalisador de matriz cerâmica. A análise elementar média pode também observar-se na Figura 3, onde se verifica que a concentração dos metais nobres é relativamente baixa. Esta composição representa uma média de dados muito variados, recolhidos da literatura e refere-se a catalisadores esgotados, portanto, produzidos já há alguns anos. Actualmente a concentração dos PGM's nos novos catalisadores é substancialmente mais baixa.

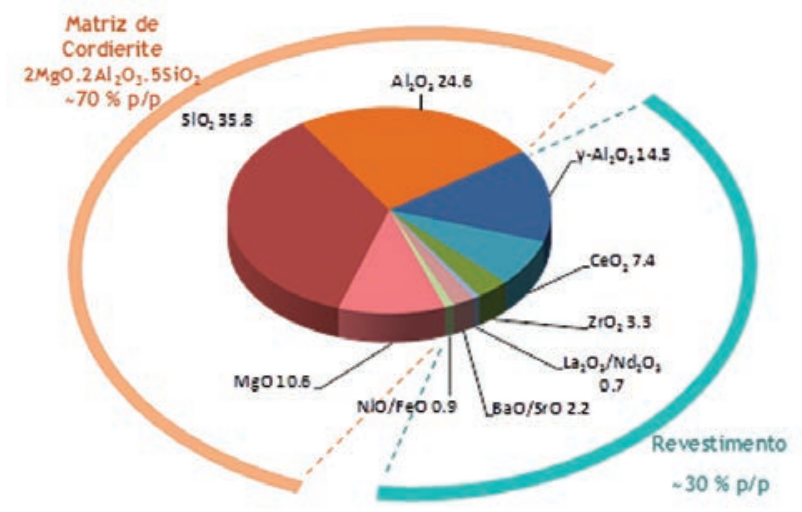

Figura 2 - Composição ponderal típica dos principais componentes de um monólito cerâmico de um catalisador auto 


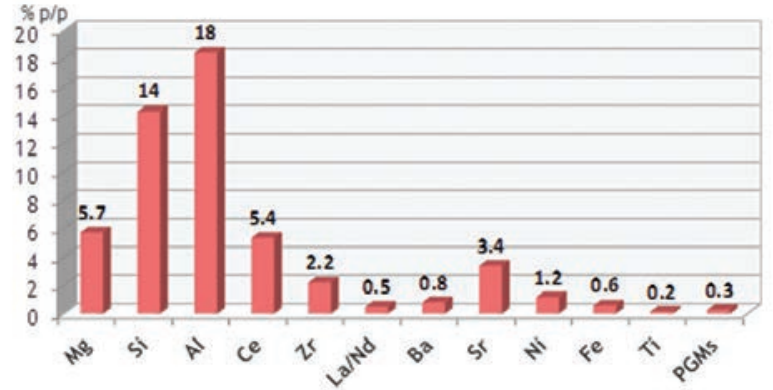

Figura 3 - Composição elementar média de um monólito de catalisador auto

\section{Metais do grupo da platina}

Os metais do grupo da platina são, no seu conjunto, substâncias críticas identificadas pela UE [4,5], devido à sua escassez, ao risco de fornecimento, e às suas características únicas que os tornam dificilmente substituíveis nas principais aplicações. O risco de fornecimento para a Europa, principal mercado consumidor de PGM's, deve-se ao facto de, neste continente, não existirem recursos primários (conhecidos/exploráveis) destes metais nobres. Esse risco, associado ao factor "criticalidade", está relacionado com as características geopolíticas dos países produtores e ao factor de concentração geográfica da produção. No caso dos PGM's, a platina e o ródio são quase totalmente produzidos na África do Sul, enquanto o paládio é maioritariamente produzido na Rússia.

A escassez e as propriedades únicas destes elementos conferem-lhes um elevado valor comercial, inigualável no mercado dos metais: em 2012, o valor médio de mercado, expresso em US\$/troy oz ${ }^{(1)}$, foi de cerca de 1560 para a platina, de 1280 para o ródio, e de 650 para o paládio [6].

A procura bruta mundial de PGM's tem-se situado em valores próximos de 600 toneladas/ano [7]. A Pt e o Pd representam quase $90 \%$ desta procura. A principal aplicação destes metais é na produção de catalisadores de automóvel, sendo que outras das suas utilizações importantes são a joalharia e a electrónica [7,8] (Figura 4).

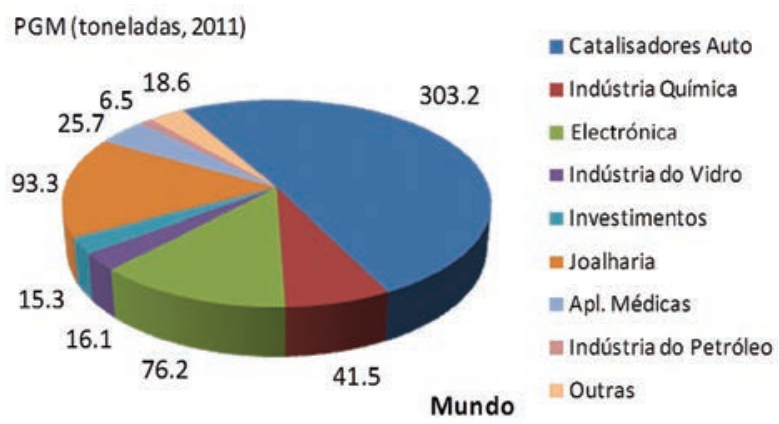

Figura 4 - Principais aplicações dos PGM’s (dados da ref. [7])

Para o futuro, há ainda que considerar as aplicações emergentes de PGM's, nomeadamente nas células de combus-

\footnotetext{
1 A onça troy (troy oz) é uma unidade de medida de massa utilizada no comércio de metais preciosos, originária de Troyes (França), que data da Idade Média e equivale a 31,1034768 g.
}

tível, que poderão fazer crescer acentuadamente a procura destes metais. Contudo, o aumento progressivo das taxas de reciclagem de produtos em fim-de-vida contendo PGM's poderá ser suficiente para satisfazer essa procura [9]. Actualmente estima-se que a taxa de reciclagem de catalisadores de automóvel, na Europa, já ultrapasse os 50\% [10].

As fontes primárias de PGM's são os sulfuretos polimetálicos, em particular os portadores de níquel e de cobre. Assim, os PGM's são processados conjuntamente com estes metais, e a sua extracção está associada às respectivas metalurgias. Nestes processos, de base pirometalúrgica [11], os PGM's são dissolvidos numa matriz de sulfuretos metálicos liquefeitos (mate), que é separada da escória e posteriormente tratada para dissolver os metais básicos $(\mathrm{Cu}, \mathrm{Ni})$, obtendo-se um resíduo rico nos PGM's que é enviado para refinarias especificamente dedicadas a estes metais nobres.

\section{Reciclagem de PGM's: Processos piro e HidROME- TALÚRGICOS}

Para os metais raros e críticos, a recuperação a partir de fontes secundárias assume-se crucial para garantir o seu fornecimento para as diversas aplicações do mercado, principalmente em regiões com escassos ou nenhuns recursos primários. Por esta razão, a reciclagem de resíduos contendo PGM's, particularmente os catalisadores de automóvel, tem conhecido um desenvolvimento importante nos últimos anos [10]. A Figura 5 ilustra as duas principais vias de tratamento de catalisadores esgotados: piro e hidrometalúrgica. O diagrama é simplificado e, portanto, não reflecte de forma exaustiva todas as tecnologias existentes, constituindo contudo uma aproximação razoável dos processos mais importantes.

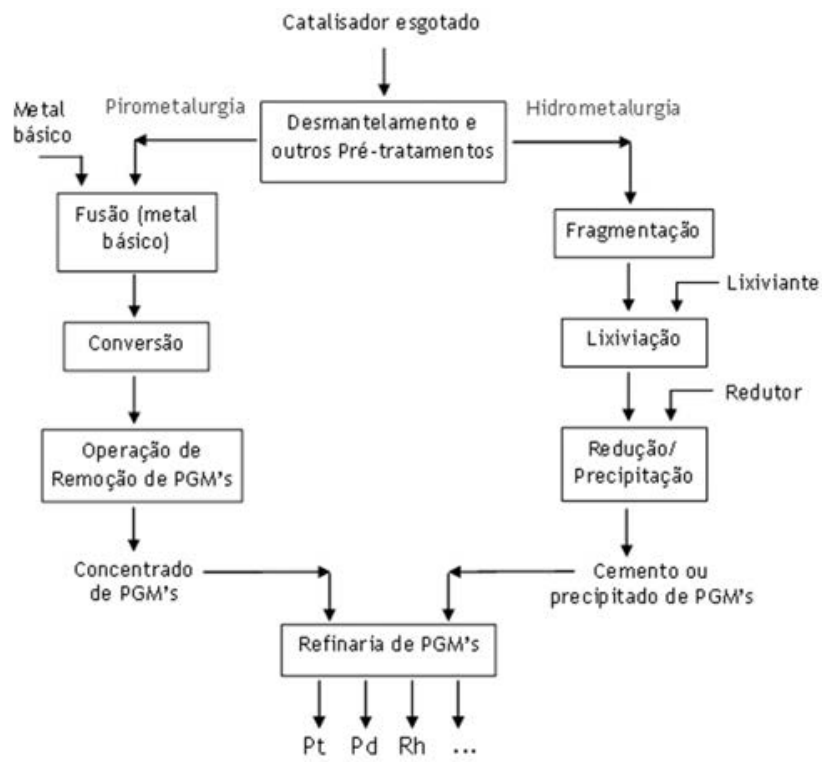

Figura 5 - Principais vias de processamento de catalisadores esgotados para recuperação dos PGM's

Os catalisadores são recolhidos e separados pelos recicladores de veículos usados e são encaminhados para o processamento metalúrgico. Nas etapas de pré-tratamento, dá- 
-se a remoção dos invólucros de aço e a fragmentação dos componentes interiores. Podem ainda operar-se alguns tratamentos térmicos para remoção de matéria orgânica, carbono e enxofre. No caso do processo subsequente ser pirometalúrgico, alguns destes pré-tratamentos podem ser desnecessários.

\subsection{Via PIROMETALÚRgICA}

No processamento pirometalúrgico podem aplicar-se diferentes tecnologias de fusão, recorrendo-se a processos pré-existentes de recursos primários/mistos (que tratam minérios e alguns resíduos), ou em alternativa utilizando fornos dedicados a resíduos (catalisadores e, eventualmente, outras fontes secundárias).

Nos fornos dedicados a fontes secundárias, os PGM’s são sempre solubilizados numa fase metálica liquefeita, adicionada para o efeito (normalmente $\mathrm{Cu}, \mathrm{Ni}$ ou $\mathrm{Fe}$ ), a temperaturas superiores a $1500{ }^{\circ} \mathrm{C}$ [12]. A matriz cerâmica é removida na forma de escória. Após operações de conversão térmica e vazamento, a fase metálica purificada é sujeita a uma operação onde o metal básico é separado dos PGM's através de dois processos alternativos: a) lixiviação do metal básico, ficando os PGM’s insolúveis concentrados num resíduo; b) electrorefinação, onde o metal (o cobre, neste caso) é solubilizado anodicamente e logo depositado num cátodo, ficando os PGM's insolubilizados na forma de uma lama (slime) que é recuperada. Os concentrados sólidos de PGM's assim gerados são conduzidos a refinadores de metais nobres.

\subsection{VIA HIDROMETALÚRGICA}

Na via hidrometalúrgica, mais versátil, menos consumidora energeticamente e vulgarmente mais adequada a menores capacidades de produção, processa-se a solubilização dos metais em meios aquosos adequados. Dada a fraca reactividade dos PGM's, devida à sua nobreza química, a sua lixiviação envolve meios fortemente concentrados. O reagente principal é, quase sempre, uma solução de ácido clorídrico, usada como fonte de cloretos para estabilizar os aquoclorocomplexos metálicos solúveis, e um agente oxidante. A matriz cerâmica é muito insolúvel, sendo então separada do licor aquoso. Esta solução contém os PGM's mas também uma série de outros metais, uns constituintes do catalisador e outros que resultam de impurezas acumuladas durante o tempo de vida deste. A redução dos PGM’s em fase aquosa é a opção mais usual para a sua separação dos restantes metais. Os redutores utilizados podem ser metais menos nobres (operação de cementação), ou outros agentes com propriedades redutoras. Obtém-se assim um precipitado, já com uma concentração razoável nos PGM's, que é depois enviado para refinação.

Na via hidrometalúrgica, após a lixiviação, pode optar-se por um processo alternativo em que os PGM's são extraídos selectivamente a partir dos licores por tecnologias sepa- rativas como a extracção por solventes. Esta opção não é muito frequente, dada a complexidade das soluções.

\subsection{RefinaÇÃo}

A refinação de metais preciosos envolve processos complexos, essencialmente hidrometalúrgicos [8], pouco conhecidos em pormenor, e que compreendem uma sucessão de operações unitárias de separação como a precipitação, a oxidação/redução, a destilação, a extracção por solventes e a permuta iónica. Pretende-se produzir os diferentes PGM's na forma metálica, com elevada eficiência e pureza. Nestas refinarias, para além dos três principais PGM's, platina, paládio e ródio, também se recuperam outros metais mais raros deste grupo, nomeadamente o ruténio, o ósmio e o irídio.

Os concentrados de PGM's, recebidos após as operações piro ou hidrometalúrgicas anteriormente descritas, são lixiviados em meio de $\mathrm{HCl}$, na presença de oxidantes fortes, sendo o cloro gasoso o agente mais utilizado [8]. Os licores obtidos são depois processados, sendo a ordem de separação e recuperação dos diversos PGM's bastante diversificada conforme o processo adoptado.

A Pt e o Pd podem ser separados através de um método clássico ainda utilizado em algumas refinarias, que consiste na sua precipitação sequencial na forma de sais amino-clorados - $\left(\mathrm{NH}_{4}\right)_{2} \mathrm{PtCl}_{6}$ e $\left(\mathrm{NH}_{4}\right)_{2} \mathrm{PdCl}_{2}$-, por adição de sais de amónio, a pH controlado. Nas fábricas mais modernas, a separação por extracção por solventes é mais utilizada. A Pt pode ser extraída usando aminas terciárias (como a tri- $n$ -octilamina) ou ésteres organofosforados (como o fosfato de tributilo). A separação do Pd pode também realizar-se usando a extracção por solventes com sulfureto de di- $n$ -octilo ou $\beta$-hidroxiloximas.

Os óxidos de ruténio e de ósmio $\left(\mathrm{RuO}_{4}\right.$ e $\left.\mathrm{OsO}_{4}\right)$ têm pressões de vapor elevadas e podem assim ser destilados com relativa facilidade. Esta tecnologia é usada em algumas refinarias para separar e recuperar estes metais, após oxidação dos mesmos usando oxidantes fortes (como cloratos ou bromatos). Estas operações podem ocorrer antes ou depois da recuperação da Pt e do Pd.

Normalmente o Rh e o Ir são os últimos metais a ser processados. Os métodos de separação são muito diversificados, desde a precipitação na forma de aminas (sais inorgânicos ou mesmo orgânicos), redução, extracção por solventes e permuta iónica.

Após separação dos PGM’s, a sua pureza não é normalmente suficiente e requer nova refinação das fracções obtidas, através de lixiviações secundárias e novas operações de purificação. Os produtos finais são sempre as respectivas formas metálicas, geradas em operações terminais de redução: em fase aquosa por adição de um agente redutor, ou por via térmica através da decomposição de sais a elevada temperatura (operação designada na gíria metalúrgica por ignição) [8]. 


\section{Recuperação de PGM's de catalisadores esgota- DOS: INVESTIGAÇÃO EM CURSO}

Com base num consórcio formado pela Universidade de Lisboa, Universidade do Algarve e Laboratório Nacional de Energia e Geologia, a equipa de autores do presente artigo está actualmente a desenvolver um projeto de I\&DT, financiado pela Fundação para a Ciência e a Tecnologia, na área da reciclagem de catalisadores automóveis, visando a recuperação dos metais preciosos neles contidos. As actividades têm sido essencialmente focadas nas operações de lixiviação e de extracção por solventes, das quais se apresentam seguidamente alguns dos resultados obtidos.

\subsection{LIXIVIAÇÃO}

A lixiviação em meio de ácido clorídrico, na presença de um oxidante genérico Ox para os três principais metais, $\mathrm{Pt}$, Pd e Rh, pode ser descrita pelas equações simplificadas representadas a seguir (o balanço de cargas não está acertado porque depende das espécies Ox/Red envolvidas).

$$
\begin{aligned}
& \mathrm{Pt}(\mathrm{s})+\mathrm{Ox}(\mathrm{aq})+6 \mathrm{HCl}(\mathrm{aq}) \rightarrow \mathrm{PtCl}_{6}{ }^{2-}(\mathrm{aq})+\operatorname{Red}(\mathrm{aq}) \\
& +6 \mathrm{H}^{+}(\mathrm{aq})
\end{aligned}
$$

$$
\begin{aligned}
& \mathrm{Pd}(\mathrm{s})+\mathrm{Ox} \mathrm{(aq)}+4 \mathrm{HCl}(\mathrm{aq}) \rightarrow \mathrm{PdCl}_{4}^{2-}(\mathrm{aq})+\operatorname{Red}(\mathrm{aq})+ \\
& 4 \mathrm{H}^{+}(\mathrm{aq}) \\
& \mathrm{Rh}(\mathrm{s})+\mathrm{Ox}(\mathrm{aq})+6 \mathrm{HCl}(\mathrm{aq}) \rightarrow \mathrm{RhCl}_{6}^{3-}(\mathrm{aq})+\mathrm{Red}(\mathrm{g}) \\
& +6 \mathrm{H}^{+}(\mathrm{aq})
\end{aligned}
$$

Nestas reaç̧ões, formam-se aquoclorocomplexos solúveis de $\mathrm{Pt}(\mathrm{IV}), \mathrm{Pd}(\mathrm{II})$ e $\mathrm{Rh}(\mathrm{III})$. Os oxidantes mais comuns propostos são $\mathrm{HNO}_{3}$, NaOCl, $\mathrm{H}_{2} \mathrm{O}_{2}$ e $\mathrm{Cl}_{2}$ [13,14]. Nestes processos, o meio cloretado apresenta duas principais vantagens: primeiro, a estabilização dos metais nobres em solução aquosa, dificilmente atingida noutro meio; segundo, a diminuição substancial dos potenciais redox dos metais nobres, quando comparados com os valores observados na ausência de iões cloreto.
Os meios lixiviantes envolvem substâncias com concentrações relativamente elevadas, só assim se conseguindo atingir rendimentos de lixiviação próximos de $90-100 \%$. Contudo, a utilização de soluções menos concentradas pode também permitir recuperações interessantes para alguns metais, embora com algumas perdas. Também se observam, vulgarmente, comportamentos diversos para os diferentes PGM's nos meios lixiviantes. A Figura 6a ilustra a eficiência de lixiviação do Pd e do Rh, a partir de catalisadores automóveis esgotados de Pd-Rh, onde se verifica que os rendimentos para o Pd são substancialmente superiores aos do Rh. Enquanto que a recuperação do Pd se mantém a níveis próximos de $90 \%$, para o Rh só se atingem rendimentos de cerca de $70 \%$. Valores superiores só seriam possíveis de obter com misturas de $\mathrm{HCl} / \mathrm{HNO}_{3}$ mais concentradas [15].

A influência da temperatura na lixiviação do Rh é muito acentuada (Figura 6b), enquanto que para o Pd o comportamento é significativamente diferente, obtendo-se elevados valores do rendimento (> 80\%) mesmo à temperatura ambiente. Para se conseguirem elevadas eficiências de lixiviação de todos os PGM's, a utilização de condições processuais agressivas (i.e. temperatura e concentração dos lixiviantes elevadas) parece assim ser fundamental.

\subsection{EXTRAÇÃO POR SOLVENTES}

A extracção por solventes (SX) é uma das tecnologias separativas mais importantes usadas em hidrometalurgia, constituindo uma operação básica em vários processos metalúrgicos industriais, tais como nas metalurgias do urânio, das terras-raras, do cobre (de minérios oxidados), do zinco, do cobalto/níquel e, claro, dos PGM's. A aplicação da SX a processos de reciclagem de metais tem também vindo, cada vez mais, a ser implementada. Num processo típico de SX, ilustrado na Figura 7, o extractante, dissolvido num solvente imiscível com a água, extrai selectivamente um metal (M1) permanecendo as restantes espécies na fase aquosa (e.g. metal M2). A fase orgânica carregada é então sujeita a uma operação inversa, a re-extracção, sendo o metal M1 recuperado numa nova fase aquosa. A fase orgâni-
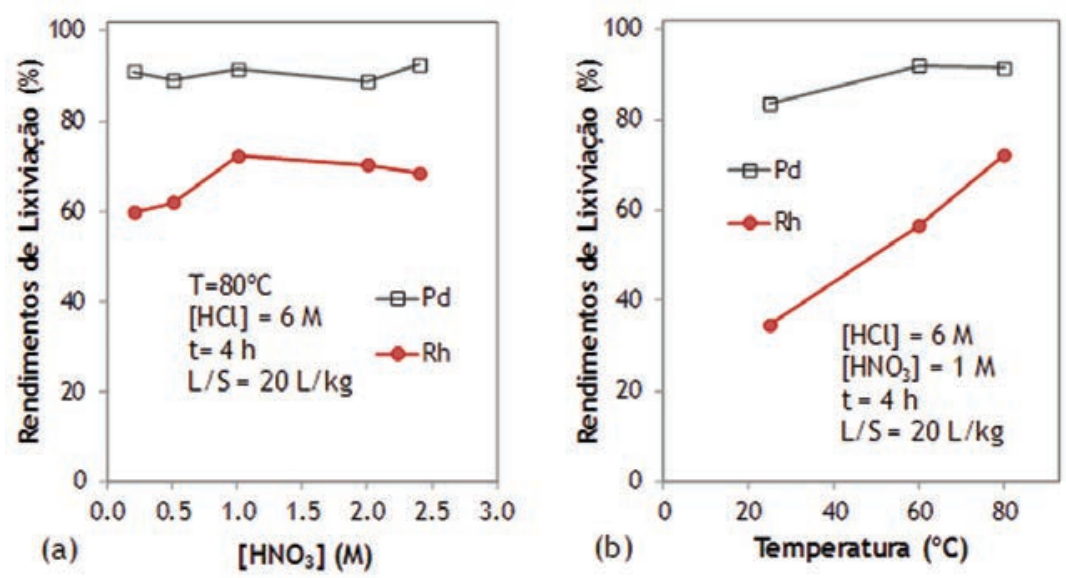

Figura 6 - Rendimentos de lixiviação de Pd e Rh a partir de um catalisador automóvel esgotado; (a) influência da concentração de $\mathrm{HNO}_{3}$; (b) influência da temperatura. (T: temperatura; t: tempo de contacto; L/S: razão líquido/sólido) 
ca, regenerada, é recirculada para a operação de extracção, permanecendo neste circuito sem consumo aparente, em teoria.

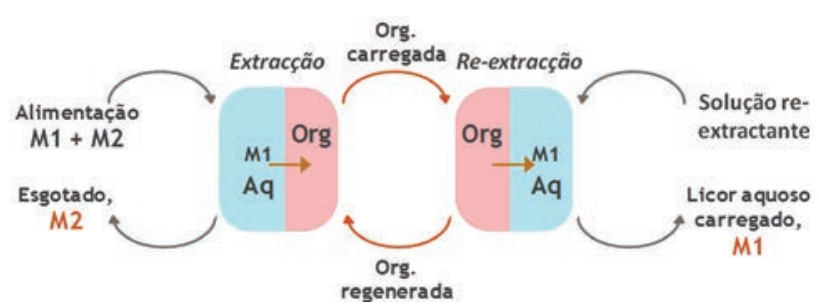

Figura 7 - Diagrama simplificado de separação dos metais M1 e M2 num circuito de extração por solventes

No âmbito do projeto de I\&DT em curso, têm-se desenvolvido reagentes extractivos da classe das amidas para os PGM's (nomeadamente Pt, Pd e Rh), com o objectivo de contribuir para a melhoria dos processos separativos e de purificação, sempre muito complexos, destes metais nobres.

A escolha das amidas como agentes extractivos, nomeadamente as malonamidas, as tiodiglicolamidas e as succinamidas, está relacionada com o principal tipo de reacção de extracção que se costuma verificar para os metais em causa. As amidas, em contacto com o meio aquoso de $\mathrm{HCl}$, podem protonar, ficando em condições de extrair espécies aniónicas presentes na fase aquosa, formando pares iónicos ou aductos. Dado que após a operação de lixiviação os PGM's estão em solução na forma de clorocomplexos aniónicos, a sua extracção pode ser realizada (Figura 8), desde que a afinidade com o extractante seja elevada, i.e., desde que a reação seja termodinamicamente favorável.
Para a segunda, que é mais eficiente a menores concentrações de $\mathrm{HCl}$, a evolução é menos pronunciada e nota-se mesmo um ligeiro decréscimo na extração para a concentração de ácido mais elevada ( $\mathrm{HCl} 8 \mathrm{M})$. Este fenómeno é por vezes observado neste tipo de sistemas de SX, e deve-se à competição entre o ião cloreto e o complexo metálico pela formação dos pares iónicos na fase orgânica.

A Figura 9b ilustra o comportamento de duas succinamidas, a $N, N^{\prime}$-dimetil- $N, N^{\prime}$-diciclo-hexilsuccinamida (DMDCHSA) e a $N, N^{\prime}$-dimetil- $N, N^{\prime}$-difenilsuccinamida (DMDPHSA) na extracção de Pt(IV) e Pd(II) de diferentes soluções aquosas de $\mathrm{HCl}$. Estes dois extractantes, que apenas diferem num dos grupos substituintes (ciclo-hexilo ou fenilo), apresentam diferentes desempenhos na extracção dos PGM's; no entanto, ambos têm maior afinidade para a $\mathrm{Pt}(\mathrm{IV})$ do que para o Pd(II). A DMDCHSA é mais eficiente na extracção dos dois iões metálicos, sendo contudo menos selectiva, principalmente para elevadas concentrações de $\mathrm{HCl}$.

Até cerca de $\mathrm{HCl} 3 \mathrm{M}$, a DMDCHSA extrai cerca de 85-90\% de Pt(IV) e menos de 5\% de Pd(II). Todavia, o aumento da concentração de ácido faz aumentar substancialmente a extracção de $\operatorname{Pd}(\mathrm{II})$, comprometendo a selectividade para a Pt(IV). Pelo contrário, a DMDPHSA mantém os níveis de selectividade Pt/Pd em toda a gama de acidez.

Na concepção dos circuitos extractivos, a operação de re-extracção é também fundamental, pois quando não é eficiente põe em causa a aplicação prática do processo. A tabela 1 ilustra o comportamento de alguns extractantes nas

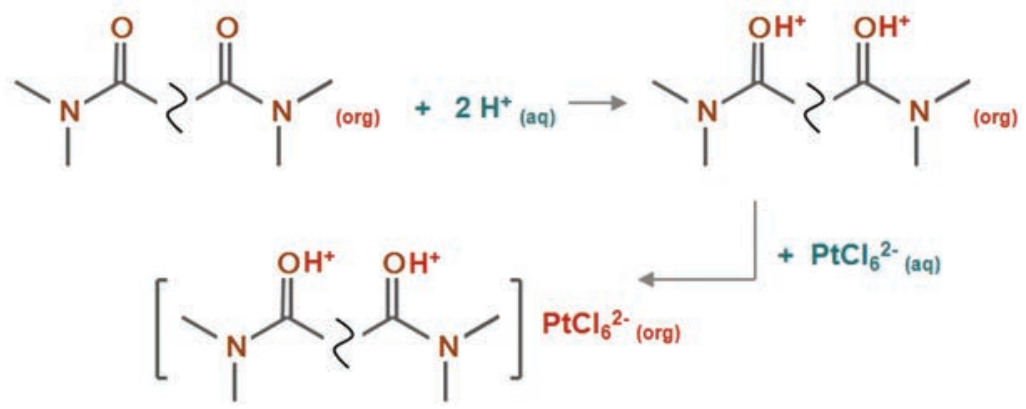

Figura 8 - Mecanismo simplificado de protonação e extracção de complexos aniónicos metálicos por diamidas, com formação de par iónico - exemplo para a Pt(IV). Os átomos de nitrogénio das diamidas estudadas encontram-se ligados a diferentes grupos alquilo

A eficiência e a selectividade de cada extractante podem ser ajustadas de acordo com as características dos grupos funcionais e também com a alteração das cadeias alquílicas substituintes [16]. A figura 9a ilustra a eficiência de extracção de Pt(IV) com duas malonamidas, a $N, N$ '-dimetil- $N, N$ '-diciclo-hexil-tetradecilmalonamida (DMDCHTDMA) e a $N, N$ '-dimetil- $N, N$ '-dibutilmalonamida (DMDBMA). O comportamento da primeira é típico dos extractantes que formam pares iónicos, pois a eficiência de extracção é significativamente promovida pelo aumento da concentração de HCl. Tal explica-se pelo aumento simultâneo da protonação do extractante e da formação de clorocomplexos metálicos aniónicos. operações de extracção e re-extracção de Pt(IV), Pd(II) e $\mathrm{Rh}(\mathrm{III})$ (resultados para contactos simples entre fases, com relações volumétricas orgânica/aquosa, $\mathrm{O} / \mathrm{A}=1$ ).

O primeiro extractante, a DMDCHTDMA, é selectivo para a Pt(IV), conseguindo extrair e separar este ião metálico dos outros PGM's, Pd(II) e Rh(III). Após extracção, a $\mathrm{Pt}(\mathrm{IV})$ pode ser recuperada eficientemente para uma nova fase aquosa numa operação de re-extracção usando uma solução diluída de $\mathrm{HCl}$.

O segundo extractante, a DMDCHTDGA ( $N, N$ '-dimetil$-N, N$ '-diciclo-hexiltiodiglicolamida) permite conceber um 

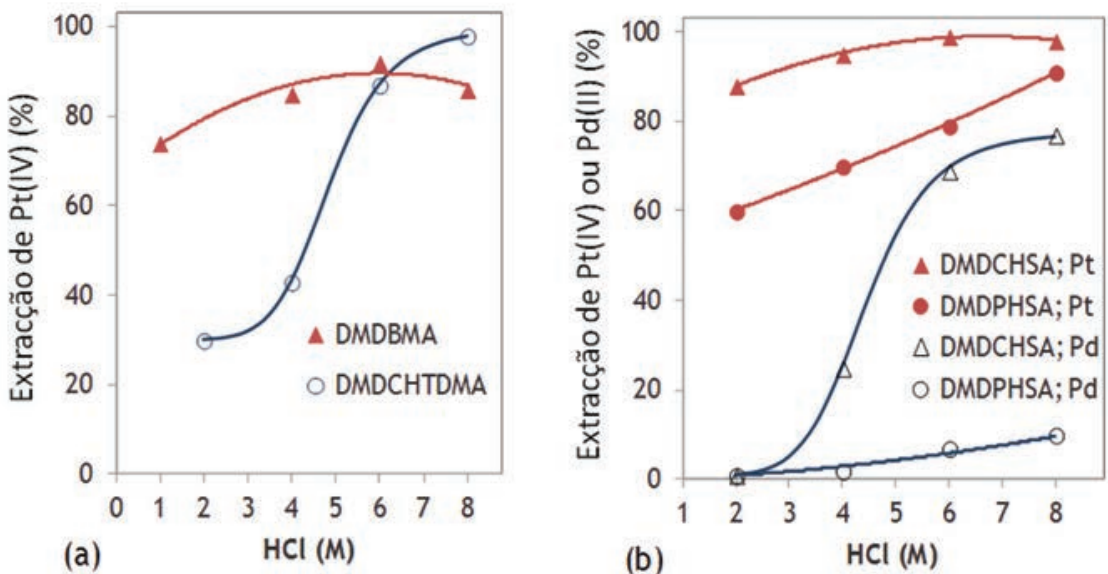

Figura 9 - Eficiência de extracção de alguns PGM’s (100 mg/L) por diamidas (0,05 M, dissolvidas em 1,2-dicloroetano), em função da concentração de HCl: (a) extraç̧ão de Pt(IV) por DMDBMA e DMDCHTDMA; (b) extraç̧ão de Pt(IV) ou Pd(II) por DMDCHSA e DMDPHSA. Condições experimentais gerais: razão de volumes das fases orgânica/aquosa (O/A) unitária, 30 minutos de contacto, 900-1000 rpm de agitação, temperatura ambiente

Tabela 1 - Eficiências de extracção e re-extracção de PGM’s (100 mg/L em HCl 6 M) com dois extractantes e diferentes agentes de re-extracção. Relação O/A = 1, 30 minutos de contacto, 900-1000 rpm de agitação, temperatura ambiente

\begin{tabular}{|c|c|c|c|c|c|}
\hline \multicolumn{2}{|c|}{ Extractante } & PGM's & $\begin{array}{c}\text { Extracção } \\
(\%)\end{array}$ & \multicolumn{2}{|c|}{ Re-extracção (\%) } \\
\hline Fórmula & Abrev. & & & \multirow{2}{*}{$\begin{array}{c}\mathrm{HCl} \\
1 \mathrm{M} \\
90\end{array}$} & \multirow{2}{*}{$\begin{array}{c}\text { tioureia } 0,1 \mathrm{M} \\
\text { em HCl } 1 \mathrm{M} \\
\text { n.a. }\end{array}$} \\
\hline & \multirow{3}{*}{ DMDCHTDMA } & $\mathrm{Pt}(\mathrm{IV})$ & 90 & & \\
\hline & & $\mathrm{Pd}(\mathrm{II})$ & 15 & $\sim 0$ & n.a. \\
\hline & & $\mathrm{Rh}(\mathrm{III})$ & $\sim 0$ & $\sim 0$ & n.a. \\
\hline & & $\operatorname{Pt}(\mathrm{IV})$ & 98 & 40 & $\sim 0$ \\
\hline & DMDCHTDGA & Pd(II) & 100 & $\sim 0$ & 83 \\
\hline & & $\mathrm{Rh}(\mathrm{III})$ & 12 & $\sim 0$ & $\sim 0$ \\
\hline
\end{tabular}

n.a. = não avaliado

circuito extractivo alternativo, em que os três PGM's podem ser separados em três fluxos diferentes. Na operação de extracção, Pt(IV) e Pd(II) são extraídos simultaneamente, ficando o Rh(III) na fracção aquosa esgotada. A separação Pt/Pd pode então ser operacionalizada na re-extracção, usando selectivamente diferentes agentes re-extractantes. Enquanto que a Pt(IV) é re-extraída com uma solução acidificada (HCl 1 M), o Pd(II) permanece na fase orgânica, podendo posteriormente ser recuperado numa nova etapa de re-extraç̧ão em meio de tioureia [17]. A extracção por solventes permite, assim, uma grande variedade de soluções de separação de PGM's, a partir de licores aquosos, possibilitando separar, purificar e gerar fluxos de metais com elevada pureza, passíveis de recuperação em formas valorizáveis.

\section{CONCLUSÕES}

A reciclagem de catalisadores esgotados de automóvel é o melhor processo de tratamento destes resíduos, tanto na pers- pectiva ambiental, como na económica, como ainda na preservação dos seus escassos recursos. Os agentes catalíticos são os metais do grupo da platina que, embora presentes em teores muito baixos, têm grande valor económico e estratégico, sendo a sua recuperação fundamental para assegurar o fornecimento destes metais no mercado. A composição dos catalisadores é complexa e requer processos de tratamento eficientes e selectivos. Quando comparado com a opção pirometalúrgica, o processamento hidrometalúrgico é versátil e adequado a pequenas capacidades de tratamento. A lixiviação em soluções de $\mathrm{HCl}$, usando um oxidante como aditivo, é um processo eficiente para solubilizar os PGM's, através da formação de clorocomplexos aniónicos solúveis. A separação e recuperação dos PGM's a partir dos licores de lixiviação podem ser conseguidas por extracção por solventes, através da utilização de derivados de diamidas como extractantes. Estas moléculas têm sido desenvolvidas de forma a permitirem elevada selectividade; assim, através de arranjos processuais adequados das operações de extracção e re-extracção, possibilita-se a separação e a recuperação eficiente destes metais. 


\section{AgradeCIMENTOS}

Este trabalho é financiado por Fundos Nacionais através da FCT - Fundação para a Ciência e a Tecnologia, no âmbito do projecto com a referência PTDC/QUI-QUI/109970/2009.

\section{REFERÊNCIAS}

[1] R.M. Heck, R.J. Farrauto, Appl. Catal. A-Gen. 221 (2001) 443-457

[2] A. Fornalczyk, M. Saternus, Metalurgija 48 (2009) 133$-136$

[3] G.C. Koltsakis, A.M. Stamatelos, Prog. Energy Combust. Sci. 23 (1997) 1-39

[4] Critical raw materials for the EU, Report of the Ad-hoc Working Group on defining critical raw materials, European Commission, 2010

[5] L. Erdmann, T.E. Graedel, Environ. Sci. Technol. 45 (2010) 7620-7630

[6] Kitco Metals Inc., 2013. (www.kitco.com, consultado em julho de 2013)

[7] J. Matthey, Platinum 2011 Interim Review, 2011

[8] F.K. Crundwell, M.S. Moats, V. Ramachandran, T.G. Robinson, W.G. Davenport, "Extractive Metallurgy of Nickel, Cobalt and Platinum-Group Metals”, Elsevier, Amsterdam, 2011

[9] M. Saurat, S. Bringezu, J. Ind. Ecol. 13 (2009) 406-421
[10] C. Hagelüken, Platin. Met. Rev. 56 (2012) 29-35

[11] R.M. Lamya, "A fundamental evaluation of the atmospheric pre-leaching section of the nickel-copper matte treatment process”, PhD Dissertation, University of Stellenbosch, South Africa, 2007

[12] R. Rumpold, J. Antrekowitsch, Recycling of platinum group metals from automotive catalysts by an acidic leaching process, Platinum'2012: Fifth International Platinum Conference 'A catalyst for change', SAIMM (The Southern African Institute of Mining and Metallurgy), Johannesburg, (2012) 695-714

[13] D.J. Aberasturi, R. Pinedo, I.R. Larramendi, J.I.R. Larramendi, T. Rojo, Miner. Eng. 24 (2011) 505-513

[14] S. Harjanto, Y. Cao, A. Shibayama, I. Naitoh, T. Nanami, K. Kasahara, Y. Okumura, K. Liu, T. Fujita, Mater. Trans. 47 (2006) 129-135

[15] C.A. Nogueira, P.C. Oliveira, G.I. Carvalho, A.M. Gonçalves, M.C. Costa, A.M.R. Costa, A.P. Paiva, Leaching behavior of platinum-group metals in spent autocatalytic converters and processes for their recovery from leachates, WASTES'2013 - $2^{\text {nd }}$ Intern. Conference Wastes: solutions, treatments and opportunities (Proc.), CVR, Guimarães, (2013) 317-322

[16] M.C. Costa, A. Assunção, A.M. Rosa da Costa, C. Nogueira, A.P. Paiva, Solvent Extr. Ion Exc. 31 (2013) 12-23

[17] A.P. Paiva, G.I. Carvalho, M.C. Costa, A.M. Rosa da Costa, C. Nogueira, Solvent Extr. Ion Exc. 32 (2014) 78-94

\section{Actualidades Científicas}

\section{Carolacton no COMBATE Às CÁRIES DENTÁRIAS}

As cáries dentárias constituem um problema de saúde à escala global. Apesar de as nossas bocas conterem uma enorme variedade de bactérias, a Streptococcus mutans é considerada o agente principal do "apodrecimento" dos dentes.

A carolacton é um produto natural (metabolito produzido por mixobactérias) que revelou possuir actividade contra a $S$. mutans quando testado em biofilmes à superfície dos quais as células aderiam, sintetizando quantidade suficiente de carolacton para os testes. Estudos iniciais permitiram verificar que este composto provoca a morte de $35-66 \%$ de

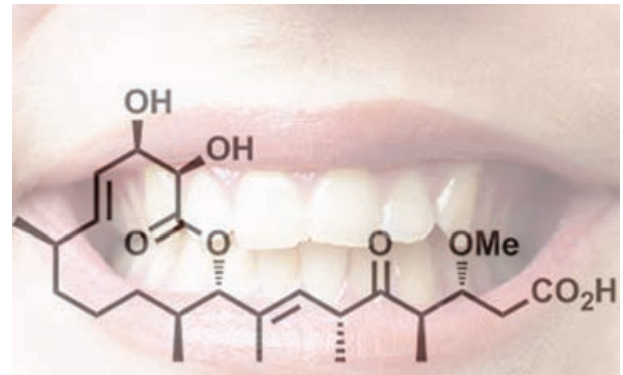
células nos biofilmes de $S$. mutans em concentrações de 5 a $25 \mathrm{ng} / \mathrm{mL}$.

Um grupo de investigadores norte-americanos desenvolveu um método de síntese da carolacton o qual consiste numa sequência reaccional de 14 passos, cada um deles com rendimento de moderado a excelente (48-99\%). A síntese inicia-se com uma $\beta$-cetoimida de Evans e inclui reacções de formação de macrociclo por esterificação, de metátese de fecho de anel e hidrogenação selectiva. A carolacton sintetizada foi submetida a testes de actividade biológica para $S$. mutans na forma de biofilme tendo revelado resultados bastante promissores. O trabalho de investigação vai agora incidir sobre o estudo da relação estrutura-função para esta classe de compostos e também na elucidação do mecanismo de acção da carolacton em biofilmes de S. mutans.

(adaptado de "Synthesis of Carolacton", http://www.chemistryviews.org/details/news/5805781/Synthesis_of_Carolacton.html acedido em 17 de Maio de 2014 e de M.S. Hallside, R.S. Brzozowski, W.M. Wuest, A.J. Phillips, Org. Lett. 16 (2014) 1148-1151).

Ana Paula Esteves (aesteves@quimica.uminho.pt) 